\title{
HOME ECONOMICS
}

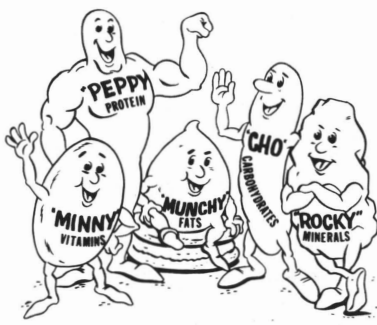

Nutrichat Series

Mention sugar and most people think of the fine white granules they spoon onto their cereal. Actually, there are over 100 substances that chemists classify as sugar. Along with starches and fiber, all sugars belong to a nutrient group called carbohydrates.

Sugars are abundant in nature, and occur naturally in milk, fruits, vegetables and grains. The main function of carbohydrates and thus sugar, is to provide energy to the body. Energy is necessary for good health, growth, proper body function and activity. Sugars found naturally in nutritious foods such as milk, fruits, vegetables and grains, supply energy; however, those foods also contain valuable amounts of vitamins, minerals, protein and fiber. Sugars, by themselves, and foods to which large amounts of sugar have been added, are mainly empty calorie foods. This means they add many calories to your diet, but do not provide the added bonus of other nutrients.

Some sugars commonly found in food include glucose, fructose, lactose, maltose and sucrose. Glucose, also called dextrose, is widely distributed in foods. Fructose or levulose, is found naturally in fruits, and therefore referred to as fruit sugar. Lactose is the sugar which occurs naturally in milk and maltose, or malt sugar, is a sugar found in grains and other starches. Sucrose, or table sugar, comes from sugar beets or sugar cane. Brown sugar and powdered sugar are different forms of sucrose.

In addition to the different forms of table sugar, some supermarkets carry maple sugar and turbinado sugar. Turbinado sugar is a partially refined sugar, erroneously called raw sugar. Syrups, honey and molasses are sweeteners that contain highly concentrated amounts of sugars. Ounce for ounce these sweeteners have approximately the same number of calories as table sugar. Honey and molasses are said to contain nutrients that are missing from table sugar, and are touted as being more nutritious. This just isn't true because all sugars and sweeteners contain many calories and no significant amounts of any nutrients.

\begin{tabular}{|c|c|}
\hline \multicolumn{2}{|c|}{ SUGARS IN FOOD } \\
\hline Food & $\begin{array}{l}\text { Approximate } \\
\text { Percent Sugar }\end{array}$ \\
\hline Most vegetables & $0-5 \%$ \\
\hline Milk (plain) & $5 \%$ \\
\hline Dried peas, dried beans and nuts & $2-7 \%$ \\
\hline Most fresh fruits & $5-15 \%$ \\
\hline Soft drinks & $10 \%$ \\
\hline Ice Cream & $20 \%$ \\
\hline Canned fruits in syrup & $20-30 \%$ \\
\hline Cookies & $30-40 \%$ \\
\hline Jelly, jam, preserves & $60 \%$ \\
\hline Dried fruit & $60 \%$ \\
\hline Molasses & $65 \%$ \\
\hline Honey & $75 \%$ \\
\hline Brown Sugar & $96 \%$ \\
\hline White Sugar & $99.5 \%$ \\
\hline
\end{tabular}

\section{Sugar Intake}

Individuals in the United States consume over 130 pounds of sugar each year. Sugars and other sweeteners can enter the diet in four basic ways-consumed in foods naturally containing them, used in home food preparation, added by food processors to many foods and beverages, and added at the table. Fifty years ago, about two-thirds of the sugar sold in the United States was purchased for home use. This meant that household members had most of the control over the amount of sugar consumed. Today the reverse is true because food processors use about two-thirds of the sugar sold in the United States. The increasing use of sugars and other sweeteners in purchased foods and beverages has taken away most of the control that household members once had over the amount of sugar eaten.

Sucrose, or table sugar, is still the most commonly 
used sugar. The use of corn syrup is increasing, especially by food processors. Honey, molasses, maple syrup and other less common sweeteners, are used by Americans only in small amounts.

The biggest consumers of sugars and sweeteners are men. The adult males over 35 years of age consume the most, followed by teenage males, the 9- to 11-year olds and finally the 20-35 year old group. Women over 35 are the lowest consumers of sugars and sugarcontaining foods.

Children get most of their sugar from candy. However, teenagers and young adults consume most of their sugar in soft drinks. In fact, much of the increased use of sugar in the United States is due to a great increase in the use of soft drinks.

\section{BEWARE! Your Breakfast Cereal May Contain More Sugar Than You Think}

It's surprising to learn from food labels how many foods contain sugars and sweeteners. Sweet taste isn't always a good guide to how much sugar has been added. Ready-to-eat breakfast cereals often contain large amounts of added sugar even if they don't taste sweet. Also, many people sprinkle large amounts of sugar on their cereal, adding to the sugar that is already there. This is especially important when we consider that many people, especially children, eat large amounts of these cereals. Children are often seen snacking on dry, presweetened cereal. Besides furnishing a lot of calories, high amounts of sugar can lead to tooth decay if proper oral hygiene is not practiced.

Pack some punch as a consumer and become aware of the amounts of sugar in your ready-to-eat breakfast cereal. Use the following guide to help you choose wisely from the cereal shelf at the supermarket.

\section{Cutting Down on Sugar}

Being aware of the sugar content of the foods you eat is the first step in cutting down. There are many practical steps you can take to limit sugars and sweeteners and, at the same time, make your diet more nutritious. These suggestions will help you feel more in control of the amount of sugars and sweeteners in your diet:

- Avoid or cut down highly-sugared foods and beverages such as soft drinks, jams, jellies, candies, syrups, ice cream and rich bakery goods.

- Use less of all forms of sugars and sweeteners including white sugar, powdered sugar and honey.

- Substitute unsweetened fruit juices, milk or water for soft drinks, punches, fruit drinks and ades which are highly sugared. Try drinking coffee and tea without sugar.
- Use fresh fruits when in season. Use fruits canned in their own juices, or light syrups instead of fruits in heavy syrup.

- Buy ready-to-eat cereals that are low in sugar and sweeten ready-to-eat cereal with fresh fruit or dried fruit instead of sugar.

- Check food labels for sweeteners and sugars in products, remembering that ingredients listed first are present in the largest amount by weight.

- When cooking or baking at home, use one-third to one-half less sugar than the recipe calls for. Changes in quality can occur so be prepared for products that look and taste a little different.

- Replace highly sugared foods and beverages with more complex carbohydrates like fresh fruits and vegetables, grain products, nuts and dried peas and beans. This replaces "empty calories" with foods rich in many of the nutrients necessary for good health and proper growth.

- Change shopping habits. Don't buy "empty calorie" foods containing high amounts of sugars and sweeteners. If they aren't in the refrigerator or kitchen cabinet, they won't be eaten as often.

- Don't reward or bribe children with sweet foods. Reward good behavior by spending some time with them.

- Splurge by buying a cookbook that features new and interesting ways to prepare fruits, vegetables, beans and grains.

- Don't replace sugars with high-fat foods or alcoholic beverages.

- Serve cakes without frosting.

- Home-processing of fruits can help you control the added sugar by canning or freezing fruits in fruit juice, light syrup or water instead of syrup.

- Also try processing fruits such as applesauce with little or no sugar.

\section{Give It a Chance}

Americans have a sweet tooth. They are used to consuming large amounts of sweet tasting foods. It may take some time to get used to foods that aren't sweet; however, people can easily learn to enjoy the natural sweetness of fruits mixed with the nut-like flavor of whole grain in cereals and bread products. A variety of natural food flavors have been masked with excessive sweetness long enough.

The U.S. Dietary Guidelines recommend that we reduce our intake of refined sugars and sweeteners to about 10 percent of our total caloric intake and increase our intake of complex carbohydrates like fruits, vegetables and grain products. Making these adjustments in your diet will decrease your caloric intake, increase your supply of nutrients and fiber, and decrease health problems associated with obesity and the lack of fiber in the diet. Why not give it a chance? 


\section{Amounts of Sugars in Ready-to-Eat Breakfast Cereals*}

\section{Cereal}

Very low sugar cereal

Puffed Rice - (QO)

Puffed Wheat - (QO)

Shredded Wheat - $(\mathrm{N})$

Cheerios - (GM)

Wheat Chex - (RP)

Corn Chex - (RP)

Rice Chex - (RP)

Kix - (GM)

Post Toasties - (GF)

Corn Flakes - (K)

Special K - (K)

\section{Low-Sugar Cereal}

Grape Nuts - (GF)

Rice Krispies - (K)

Wheaties - (GM)

Total - (GM)

Concentrate - $(\mathrm{K})$

Product 19 - (K)

Buckwheat - (GM)

$40 \%$ Bran - (GF)

Grape Nut Flakes - (GF)

Team - (N)

Life - (QO)

Fortified Oat Flakes (GF)

All Bran - (K)

\section{Medium-Sugar Cereal}

$100 \%$ Bran - $(\mathrm{N})$

Life, Cinnamon - (QO)

Country Crisp - (GF)

Frosted Mini-Wheats - (K)

C. W. Post - (GF)

C. W. Post, Raisin - (GF)

Raisin Bran -. (K)

Cracklin Bran - (K)

Golden Grahams - (GM)
Total \% Sugar

Cereal

8.3

9.3

9.9

12.2

13

13.3

14.1

16

18.5

19 Human Nutrition Center, USDA.
Raisin Bran - (GF)

Cap'n Crunch, peanut butter - (QO)

Cocoa Puffs - (GM)

Trix - (GM)

Frosted Rice - (K)

Honey Comb - (GF)

Alpha Bits - (GF)

Count Chocula - (GM)

High-Sugar Cereal

Cap'n Crunch - (QO)

Cookie Crisp, Oatmeal - (RP)

Crazy Cow, Strawberry - (GM)

Quisp - (QO)

Total \% Sugar

30.4

32.3

33.3

35.9

37

37.2

38

39.5

40

40.1

40.1

40.7

41

41

42.2

42.5

42.6

43

Cocoa Krispies - (K)

Cap'n Crunch, Crunch Berries - (QO)

43.3

43.5

43.7

44

45.5

45.6

46

46

48

54.6

56

Sugar Smacks - (K)

*Letters in parentheses following cereal name indicate manufacturer: General Foods (GF), General Mills (GM), Kellogg $(\mathrm{K})$, Nabisco (N), Quaker Oats (QO), Ralston-Purina (RP).

Source: "Analysis of sugar content of 62 ready-to-eat cereals." Nutrient Composition Laboratory, Nutrition Institute, 
- Issued in furtherance of Cooperative Extension Work Acts of May 8 and June 30, 1914 in cooperation with the United States Department of Agriculture. Leonard C. Douglas, Director, Cooperative Extension Service, University of Missouri and Lincoln University, Columbia, Missouri 65211. An equal opportunity institution.

File: Nutrition $3 / 83 / 5 M$ 